\title{
Self-assembly and Mechanism of L-Alanine-based Dihydrazide Derivative as Excellent Gelator of Organic Solvents
}

\author{
Chuan-Sheng Wang, ${ }^{\dagger \neq, *,}$ Xiao-Hong Wang, ${ }^{\ddagger}$ Zhi-Yuan Li, ${ }^{\ddagger}$ Wei Wei, ${ }^{\ddagger}$ Zhong-Liang Shi, ${ }^{\ddagger}$ and Zhi-Tong Sui ${ }^{\dagger}$ \\ ${ }^{\dagger}$ School of Materials and Metallurgy, Northeastern University, Shenyang 110004, China. *E-mail: wchsh18@163.com \\ ${ }^{\star}$ Department of Chemistry, Shenyang University of Chemical Technology, Shenyang 100142, China \\ Received January 10, 2011, Accepted February 13, 2011
}

\begin{abstract}
A new organogelator, L-Alanine dihydrazide derivative can self-assemble in various organic solvents and turned them into thermally reversible physical supramolecular organogels at extremely low concentrations $\left(<2\right.$ wt \%). The gel-sol phase transition temperatures $\left(\mathrm{T}_{\mathrm{GS}}\right)$ were determined as a function of gelator concentration and the corresponding enthalpies $\left(\Delta H_{g}\right)$ were extracted. Scanning electron microscopy (SEM) measurements revealed that the interspaces of fiber-like network structures were diminished with the increasing of the LMOG concentration. FT-IR spectroscopy studies revealed that hydrogen-bonding and hydrophobic interaction were the driving forces for the formation of the gels. Based on the data of XRD and molecular modeling, the possible packing modes for the formation of organogelator aggregates were proposed.
\end{abstract}

Key Words : L-Alanine, Hydrazide derivatives, Organogel, Gelator, Self-assembly, Hydrogen bonding

\section{Introduction}

During the past decades, low-molecular-weight organic gelators (LMOGs) have attracted much interest due to their unique properties and potential applications as semi-solid systems. ${ }^{1-6}$ It is well known that most organogelators can self-assemble into nanoscale superstructures such as fibers, ribbons, schistose, rods, and so on through intra and/or intermolecular non-covalent interactions such as hydrogen bonding, $\pi-\pi$ stacking, van der Waals forces and charge transfer interactions. ${ }^{7,8}$ These nanostructures further entangled or bundled to form a 3D network and immobilize the solvents. In comparison with polymer organogels, supramolecular organogels are usually thermoreversible. Owing to their unique behavior the organogels and organogelators have been used as organic templates for the nanoscale designed inorganic materials ${ }^{9-12}$ and fabrication of mesoporous polymer materials. ${ }^{13}$ Moreover, they have been applied as liquid crystals $^{14}$ and in photochemistry ${ }^{15}$ and electrochemistry. ${ }^{16-18}$ In addition, gelators have been developed not only as academic interests but also for industrial fields, such as cosmetics, textiles, foods, health care, and oil recovery. ${ }^{1-6}$

In order to form organic gels, the design of LMOGs molecules is of pivotal important. So far, it is still difficult to predict the gelation property simply based on the molecular structures. However, various groups are suggested to be effective in constructing gelator molecules. For example, the amide and urea groups are usually used as the hydrogen bonding units. The aromatic rings are generally adopted to act as the $\pi-\pi$ stacking as well as hydrophobic units. Alkyl chains usually worked as the hydrophobic building blocks. ${ }^{19}$ Amino acids, which can supply chiral centers, are among one of the most used building units for the design of gelators. Various gelators based on the amino acids have been reported recently. ${ }^{20,21}$ According to this condition a new chiral gelator $\mathrm{N}$-Carbobenzoxy-L-Alanine-Hexadecane Hydrazide (designated as Cbz-Ala-HdHz, the molecular structure is shown in Scheme 1), which contains L-Alanine, carbobenzoxy, dihydrazide and long alkyl chain units, was designed and synthesized. We studied their gelling behaviors in different organic solvents and investigated their gels strength by using the dropping ball method. The morphology and formation mechanism of supramolecular organogels in the presence of the Cbz-Ala-HdHz was investigated by using SEM, FT-IR, and X-ray Diffraction (XRD).

\section{Experimental Section}

L-Alanine ethyl ester hydrochloride, carbobenzoxy chloride (Cbz-Cl), n-hexadecanoyl chloride were purchased from Yangzhou Baosheng Biochemical Co., Ltd. and used as received. Hydrazine hydrate was obtained form Tianjin Bodi Chemical Co., Ltd. The other chemicals were of the highest commercial grade available and used without further purification. All solvents used in the syntheses were purified, dried, or freshly distilled as required.

Preparation of Cbz-Ala-HdHz. L-Alanine ethyl ester hydrochloride (7.68 g, $50 \mathrm{mmol}$ ) was dissolved in $\mathrm{NaHCO}_{3}$
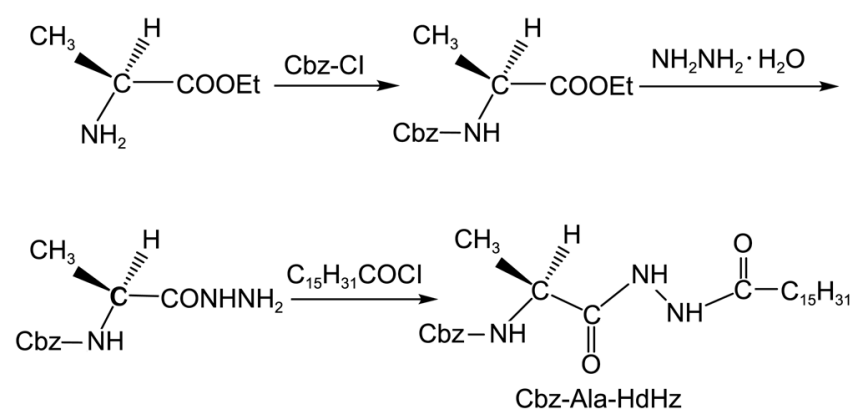

Scheme 1. The synthetic route of low-molecular-weight gelator. 
saturated aqueous solution then carbobenzoxy chloride $(\mathrm{Cbz}-\mathrm{Cl})(8.53 \mathrm{~g}, 50 \mathrm{mmol})$ was slowly added to the solution and stirred at room temperature for $19 \mathrm{~h}$. The solution was extracted by ether. The organic layer was washed with water thoroughly, and dried on anhydrous $\mathrm{MgSO}_{4}$. After filtration, the solvent was removed under reduced pressure to afford Cbz-L-Ala-OEt as a colorless and transparent oily liquid. A mixture of Cbz-L-Ala-OEt $(10.05 \mathrm{~g}, 40 \mathrm{mmol})$ and hydrazine hydrate $(7.50 \mathrm{~g}, 120 \mathrm{mmol})$ in ethanol $(100 \mathrm{~mL})$ was stirred for $16 \mathrm{~h}$ under reflux. The solvent was removed under reduced pressure. The residue was dissolved in chloroform. The solution was washed with brine thoroughly, and dried on anhydrous $\mathrm{MgSO}_{4}$. After filtration, the solvent was removed under reduced pressure to afford Cbz-L-Ala-hydrazine as a white solid. To a solution of Cbz-L-Ala-hydrazine $(7.12 \mathrm{~g}, 30 \mathrm{mmol})$ in chloroform $(150 \mathrm{~mL}), n$-hexadecanoyl chloride $(8.25 \mathrm{~g}, 30 \mathrm{mmol})$ was added. The reaction mixture was stirred for $6 \mathrm{~h}$ at room temperature followed by the removal of the solvent under reduced pressure. The final product Cbz-Ala- $\mathrm{HdHz}$ was recrystallized for three times with 1:1 mixture of ethanol-ethyl acetate, and the product was obtained in a yield $80 \%$ above. FT-IR $\left(\mathrm{KBr}, \mathrm{v}, \mathrm{cm}^{-1}\right)$ $3382(\mathrm{~N}-\mathrm{H}$, amide A), $3218(\mathrm{~N}-\mathrm{H}$, amide $\mathrm{A}), 1694(\mathrm{C}=\mathrm{O})$, $1614\left(\mathrm{C}=\mathrm{O}\right.$, amide I), $1526\left(\mathrm{~N}-\mathrm{H}\right.$, amide II). ${ }^{1} \mathrm{H}$ NMR $(\mathrm{DMSO}, 600 \mathrm{MHz}) \delta 9.82\left(\mathrm{~s}, 1 \mathrm{H} ; \mathrm{NHCO}\left(\mathrm{CH}_{2}\right)_{14}\right), 9.73(\mathrm{~s}$, $1 \mathrm{H}$; Ala-NH), 7.50 (d, $J=7.7,1 \mathrm{H} \mathrm{Cbz-NH}), 7.31-7.38$ (m, $5 \mathrm{H} ; \mathrm{Ph}-\mathrm{H}), 5.01\left(\mathrm{~s}, 2 \mathrm{H} ; \mathrm{Ph}-\mathrm{CH}_{2}\right), 4.16-4.01(\mathrm{~m}, 1 \mathrm{H}$; $\left.\mathrm{CHCH}_{3}\right), 2.08\left(\mathrm{t}, J=7.3,2 \mathrm{H} ; \mathrm{CH}_{2}\left(\mathrm{CH}_{2}\right)_{13} \mathrm{CH}_{3}\right), 1.48(\mathrm{~m}$, $\left.2 \mathrm{H} ; \mathrm{CH}_{2}\left(\mathrm{CH}_{2}\right)_{12} \mathrm{CH}_{3}\right), 1.26-1.21\left(\mathrm{~m}, 27 \mathrm{H} ; \mathrm{CH}_{2}\left(\mathrm{CH}_{2}\right)_{12} \mathrm{CH}_{3}\right.$, $\left.\mathrm{CHCH}_{3}\right), 0.85$ (t, $J=6.9,3 \mathrm{H} ; \mathrm{CH}_{2} \mathrm{CH}_{3}$ ). LC-MS $m / z 498.5$ $[\mathrm{M}+\mathrm{Na}]^{+}$.

Characterization. Scanning electron microscopy (SEM) images of the xerogel were obtained using a JEOL JSM$6360 \mathrm{LV}$ scanning electron microscope. The accelerating voltage was $10 \mathrm{kV}$. The heated $\mathrm{Cbz}-\mathrm{Ala}-\mathrm{HdHz}$ solution spread on a glass plate was allowed to cool to room temperature. After freeze-drying with liquid nitrogen, the xerogel (Cbz-Ala-HdHz aggregates) was subjected to SEM observation. Fourier transform infrared (FT-IR) spectra measurements were recorded on a Nicolet Nexus 470. FT-IR spectroscopy was performed in a spectroscopic cell with a $\mathrm{CaF}_{2}$ window and $50-\mu \mathrm{m}$ spacers operating at a $2 \mathrm{~cm}^{-1}$ resolution with 32 scans for solution and the $\mathrm{KBr}$ method for gel states. X-ray diffraction pattern was performed using a Bruker D8 ADVANCE instrument using $\mathrm{CuK} \alpha \mathrm{X}$ radiation from $0.5^{\circ}$ to $40^{\circ}(2 \theta)$ in steps of $0.05^{\circ}$. The preparation of sample was similar to that of the SEM samples.

\section{Results and Discussion}

Gelation Properties. The Cbz-Ala-HdHz was readily soluble in different organic solvents on increasing the temperature. When the solutions were allowed to cool to room temperature slowly, translucent or opaque gels are obtained within a few minutes. The gelating propensity of these reported L-Alanine dihydrazide derivative in a wide range of organic solvents including vegetable oils, alcohols, esters, aromatic solvents and tetrachloromethane was studied by dissolving a small amount $(0.1-3.0 \mathrm{wt} \%)$ of compound in $2 \mathrm{~mL}$ of the desired solvent under heating. Upon cooling to $25^{\circ} \mathrm{C}$, the complete volume of the respective solvent was immobilized and a gel was formed. The gelation was confirmed by the inverted test tube method. ${ }^{22}$ In a given solvent, gelation occurred when a critical concentration, called critical gelation concentration (CGC), of the gelator is reached. At room temperature and at gelator concentration close to CGC it took 3-5 h for the gelation to take place. However, the gelation time decreased drastically when gelator concentration was increased above CGC. The results of gelation studies in various solvents are summarized in Table 1 . These gels are stable toward shaking and they are also stable for a few weeks at room temperature $\left(25^{\circ} \mathrm{C}\right)$. Cbz-Ala- $\mathrm{HdHz}$ did not dissolve at all in some aliphatic solvents with a lower polarity, such as $n$-hexane, ether, even after prolonged heating at the temperature to the boiling point of the solvents. Although this gelator has excellent gelation ability, it is a fact that a given gelator can gelatinize certain solvents. Generally, the gelation ability of the gelator is related to the interaction between gelator and solvent molecules, governed by molecular polarity and the respective structural factors. The excellent gelation ability of Cbz-Ala-HdHz could be attributable to its special molecular structure. Amide groups of Cbz-Ala-HdHz provided sites of hydrogen-bonding formation. Aromatic benzene ring and long alkyl chain of Cbz-Ala-HdHz provided $\pi-\pi$ stacking interaction and molecular flexibility for aggregation and assembly in organic media.

Gel Stability Studies. Thermal stabilities of the Cbz-Ala$\mathrm{HdHz}$ gels were analyzed by the dropping ball method. ${ }^{23-25}$ The thermal stabilities of these gels increased upon increasing the concentration of the gelator. In this study, Cbz-Ala-

Table 1. Gelation ability of Cbz-Ala-HdHz in organic solvents

\begin{tabular}{lccc}
\hline Solvent & CGC & State & $\Delta H g\left(\mathrm{~kJ} \mathrm{~mol}^{-1}\right)$ \\
\hline Soybean oil & 0.2 & TG & 71.9 \\
Castor oil & 0.3 & TG & 46.4 \\
Olive oil & 0.2 & TG & \\
Benzene & 0.9 & TG & \\
Toluene & 0.7 & TG & \\
Chlorobenzene & 0.4 & TG & 115.4 \\
$o$-Xylene & 0.5 & TG & 81.3 \\
$p$-Dioxane & & P & \\
Ethylene glycol & 0.4 & OG & \\
$n$-Pentanol & 0.7 & OG & \\
$n$-Hexanol & 0.6 & OG & \\
Butyl acetate & 1.6 & OG \\
$n$-Hexane & & Ins & \\
Ether & & Ins \\
Tetrachloromethane & 0.4 & TG \\
Chloroform & 1.7 & TG & \\
\hline
\end{tabular}

Note: CGC: critical gelation concentration in wt \%; TG: transparent gel; OG: opaque gel; Ins: insoluble (not fully soluble at $3.0 \mathrm{wt} \%$ ); P: Precipitation. 

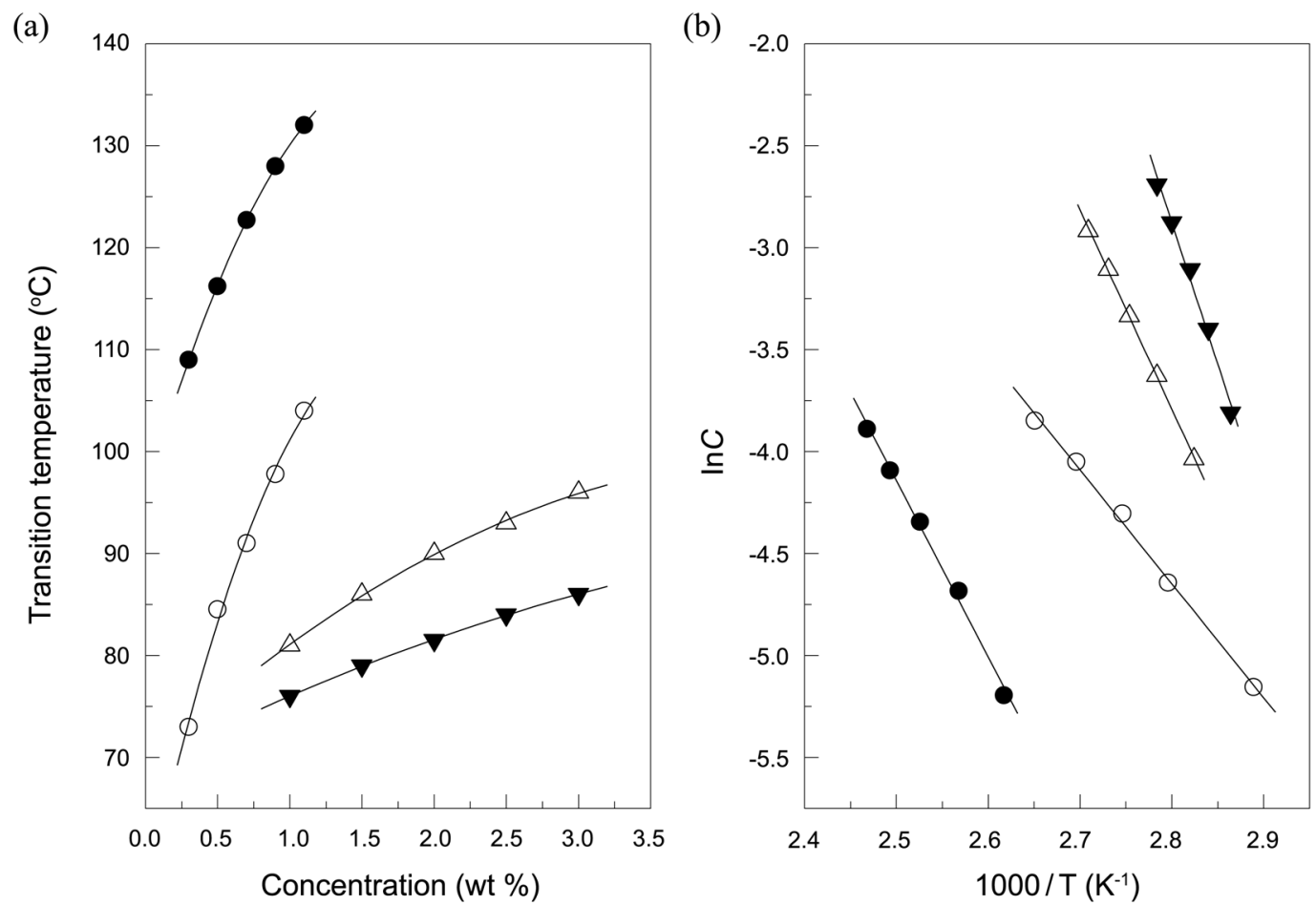

Figure 1. Gel-to-sol phase transition temperature $\left(\mathrm{T}_{\mathrm{GS}}\right)$ of Cbz-Ala-HdHz as a function of gelator concentration in soybean oil $(\bullet)$, castor oil $(O), o$-xylene $(\triangle)$ and chlorobenzene $(\boldsymbol{\nabla})$, respectively.

$\mathrm{HdHz}$ in different solvents follows the similar trend wherein the melting temperatures of the gel were found to increase with increasing gelator concentration. The gel-sol phase transition temperatures $\left(\mathrm{T}_{\mathrm{GS}}\right)$ of $\mathrm{Cbz}-\mathrm{Ala}-\mathrm{HdHz}$ in chlorobenzene, $o$-xylene, soybean oil and castor oil are plotted against the gelation concentration in Figure 1(a). The thermo- dynamic analysis for the gel-sol transition was carried out using a van't Hoff relationship. ${ }^{26}$ From the relationship between $\mathrm{T}_{\mathrm{GS}}$ and corresponding concentration, the gel-sol transition enthalpy $\left(\Delta H_{g}\right)$ was determined from the slope of $\ln C_{g}$ versus $\left(\mathrm{T}_{\mathrm{GS}}\right)^{-1}$. The plots are represented in Figure 1(b) and the resulting enthalpy values in various solvents are
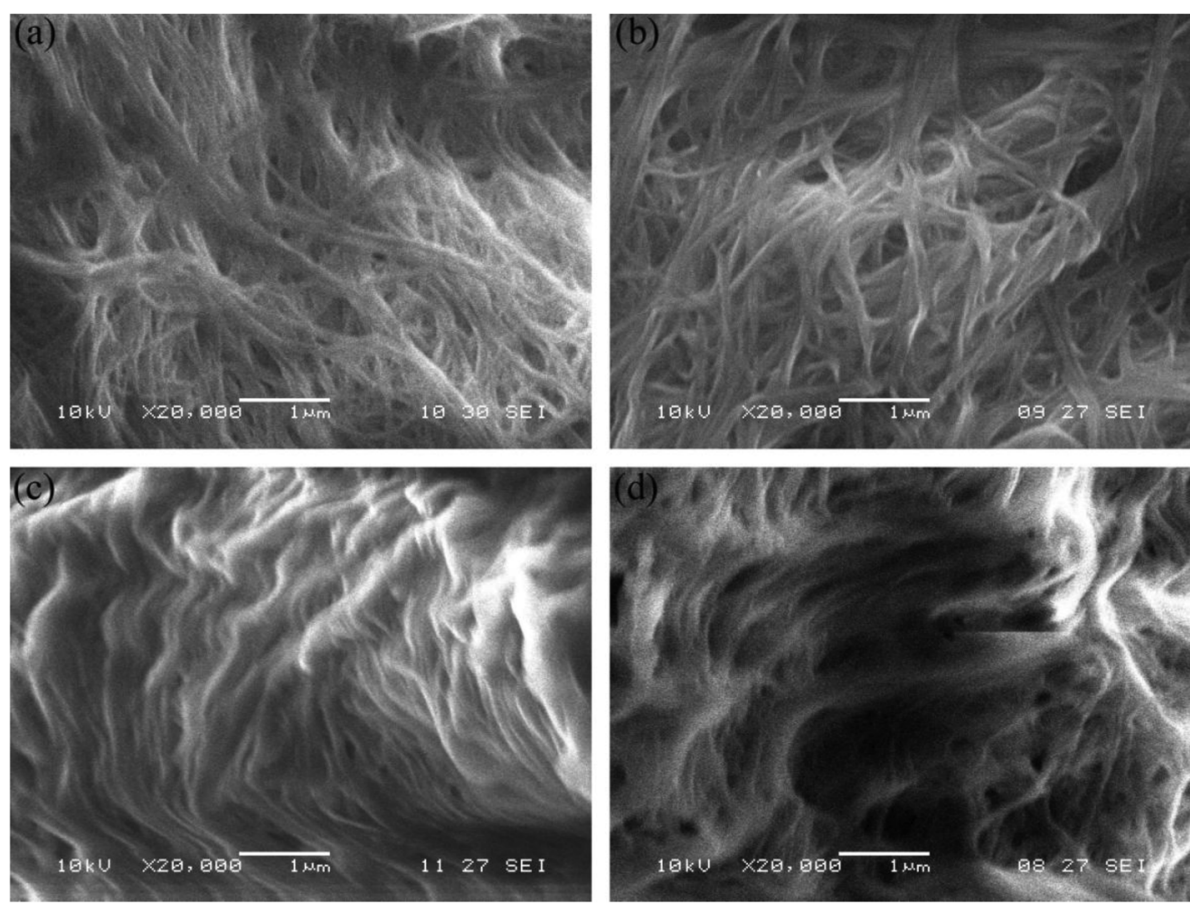

Figure 2. SEM images of xerogels formed by (a) $1.5 \mathrm{wt} \%$ (c) $2.5 \mathrm{wt} \%$ Cbz-Ala-HdHz in chlorobenzene, and (b) $0.5 \mathrm{wt} \%$ (d) $1.5 \mathrm{wt} \%$ Cbz-Ala-HdHz in $o$-xylene. Magnitudes are 20,000 $\times$. 
summarized in Table 1.

Morphology of the Gels. Molecular self-assembly at the micro level can be observed using scanning electron microscopy (SEM). This technique provides a comparative visual technique to assess the impact of the spacer unit on the mode of self-assembly. ${ }^{27}$ Figure 2 shows SEM images of Cbz-Ala$\mathrm{HdHz}$ xerogel obtained from chlorobenzene and $o$-xylene in different concentration. As shown in Figure 2(a) and Figure 2(b) (low concentration), the Cbz-Ala-HdHz molecules spontaneously self-assembled into entangling fiber-like aggregates with diameters of $c a$. 60-150 nm through non-covalent interactions and further form random three-dimensional networks, and its length can be extended to tens of micrometers. However, in Figure 2(c) and Figure 2(d) (high concentration), the similar three-dimensional network structure have much smaller interspaces than that of low concentration. However, the concentration of the gelator influenced the size of the fibers very slightly. The diameter of fibers almost did not increase with the increasing of the concentration of the gelator. This change in scale means that a small amount of solvent molecules need to be imprisoned in each interspaces. This might be the reason why gels in higher LMOG concentration have much better stability.

FT-IR Studies. In order to evaluate the driving forces for gelation, we measured the FT-IR spectra. Figure 3 shows the FT-IR spectra of Cbz-Ala-HdHz in chloroform solution and in chloroform gel. In chloroform solution, the typical IR bands, arising from non-hydrogen bonded amide groups, were observed at 3444 (amide A), 1628 (amide I) and 1529 $\mathrm{cm}^{-1}$ (amide II). The IR spectra of chloroform gel showed the bands at 3282, 3209 (amide A), 1603 (amide I), and $1542 \mathrm{~cm}^{-1}$ (amide II), characteristics of hydrogen bonded amide groups. In addition, the IR bands of urethane group appeared at $1695,1673 \mathrm{~cm}^{-1}$ in chloroform solution and $1693,1675 \mathrm{~cm}^{-1}$ in chloroform gel. Such IR shifts indicate the formation of the intermolecular hydrogen bonding interaction between the amide groups and between the urethane groups. ${ }^{28-31}$

The absorption bands arising from the alkyl chains, anti-

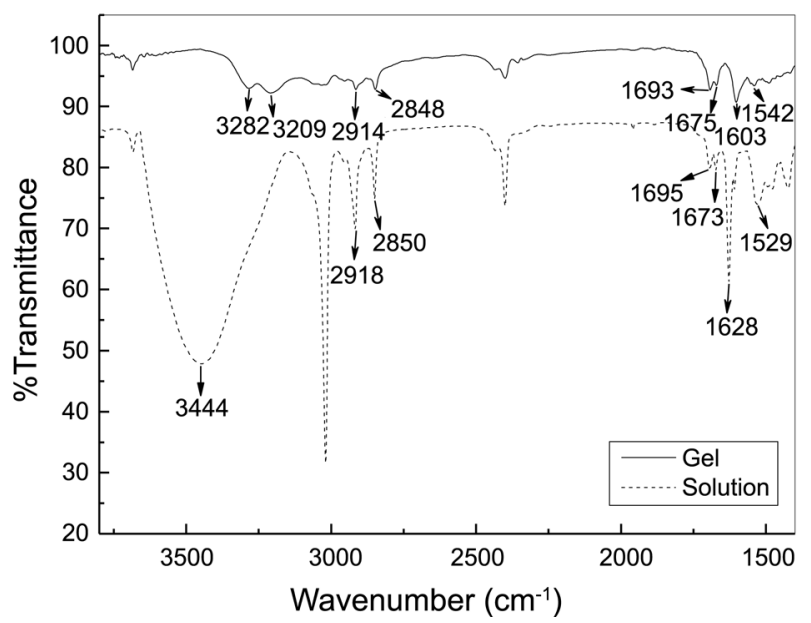

Figure 3. FT-IR spectra of Cbz-Ala-HdHz in chloroform solution ( $0.1 \mathrm{wt} \%$, dashed line) and chloroform gel (2.0 wt \%, solid line).

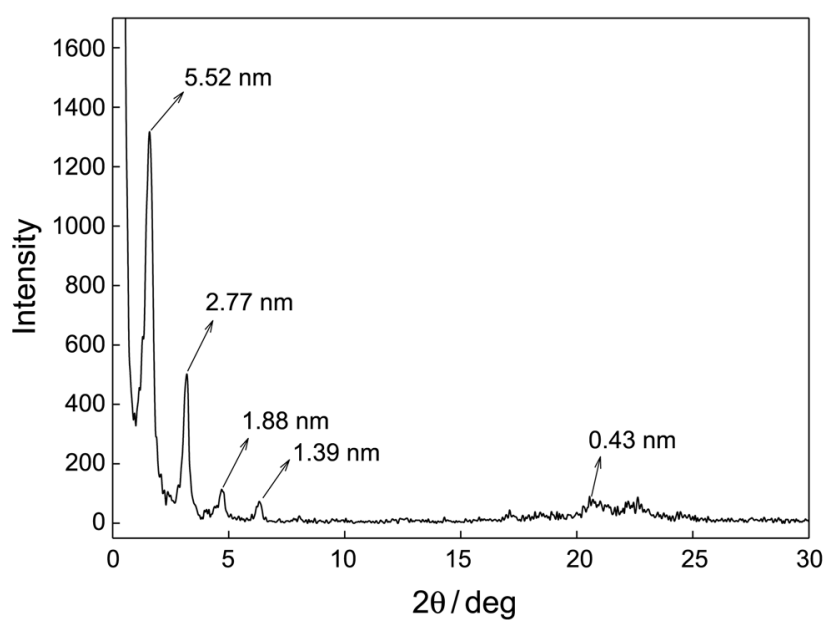

Figure 4. X-ray diffraction pattern of the chlorobenzene xerogel formed by $1.5 \mathrm{wt} \% \mathrm{Cbz}-\mathrm{Ala}-\mathrm{HdHz}$.

symmetric $\left(v_{\mathrm{as}}, \mathrm{C}-\mathrm{H}\right)$ and symmetric $\left(v_{\mathrm{s}}, \mathrm{C}-\mathrm{H}\right)$ stretching vibrations, appeared at the low wavenumbers, $2914 \mathrm{~cm}^{-1}$ and $2848 \mathrm{~cm}^{-1}$, compared with those of Cbz-Ala-HdHz in chloroform solution. Such IR shift suggested that the alkyl groups of Cbz-Ala-HdHz were organized in the self-assembled nanostructure via hydrophobic interaction. ${ }^{28,29}$ Therefore, the driving forces for the formation of a hydrogel are mainly hydrogen bonding and complementarily hydrophobic interaction.

X-ray Diffraction Studies. The X-ray diffraction pattern (Fig. 4) of the xerogel of Cbz-Ala-HdHz shows periodical diffraction peaks. The obtained long Bragg distance (d) of the xerogel of Cbz-Ala-HdHz are 5.52, 2.77, 1.88, and 1.39 $\mathrm{nm}(1,1 / 2,1 / 3,1 / 4)$, indicating that Cbz-Ala-HdHz selfassembles into a lamellar structure. ${ }^{32}$ From the optimized
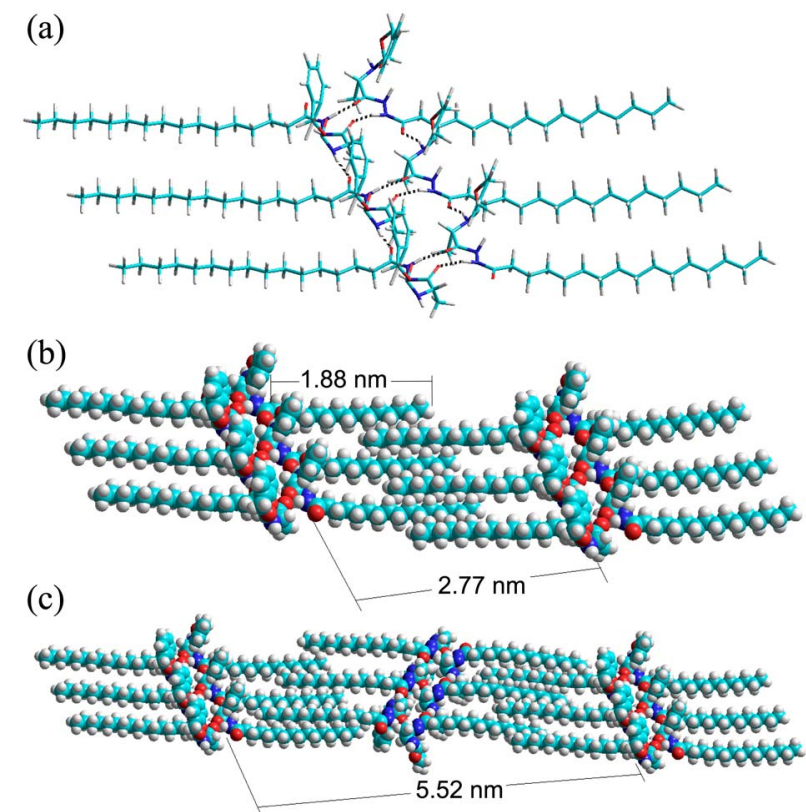

Figure 5. Energy-minimized structures of Cbz-Ala-HdHz and the possible packing modes for the aggregates in organic solvents. Dashed lines represent hydrogen bonding interactions. 
HyperChem 8.0 model, the long alkyl chain length of CbzAla-HdHz $(1.87 \mathrm{~nm})$ is closely consistent with the third long Bragg distance $(1.88 \mathrm{~nm})$. Thus, we can deduce that the long alkyl chains parallel-aligned and then composed a surface. The second long Bragg distance $(2.77 \mathrm{~nm})$ is longer than the long alkyl chain lengths and twice shorter than the long alkyl chain lengths. Based on this correspondence, the long axes of the Cbz-Ala-HdHz molecules should be in an interdigitated arrangement. The first long Bragg distance (5.52 $\mathrm{nm}$ ) is nearly twice as long as the second long Bragg distance $(2.77 \mathrm{~nm})$, it can be deduced that the gel aggregates consist of a repeating bilayer unit, which bears the center-to-center packing model with interdigitated arrangement alkyl chains relative to the bilayer normal. Within the bilayer unit, the molecules are connected by inter-layer hydrogen bonds to form a hydrogen bond network and then develop the superstructure that is schematically shown in Figure 5(a). For the random arrangement of the bilayer unit, it may cause two different packing modes which are shown in Figure 5(b) and Figure 5(c).

\section{Conclusion}

A new organogelator Cbz-Ala-HdHz based on L-Alanine was synthesized. Through the gelling behaviors studies, we have demonstrated that L-Alanine dihydrazide derivative is excellent gelator in various organic solvents. The organogelater was able to self-assemble into nano-fiber architectures in different solvents. The FT-IR results indicate that the main driving forces for self-assembly is hydrogen-bonding and hydrophobic interaction. Based on the data of XRD and molecular modeling, the possible molecular packing modes for organogelator aggregates were proposed. Most of the gels of vegetable oils have higher gel-sol transition temperature and lower CGC, and the gelation process was observed to be thermoreversible. Amino acid-based gelators are mostly found to be biocompatible and biodegradable in nature. Thus the organogels may find applications in drug delivery. Work in this direction is being carried out in this laboratory.

Acknowledgments. This research work is financially supported by the National Natural Science Foundation of China (No. 30772670).

\section{References}

1. Terech, P.; Weiss, R. G. Chem. Rev. 1997, 97, 3133.

2. Estroff, L. A.; Hamilton, A. D. Chem. Rev. 2004, 104, 1201.

3. George, M.; Weiss, R. G. Acc. Chem. Res. 2006, 39, 489.
4. van Esch, J. H.; Kellogg, R. M.; Feringa, B. L. Angew. Chem. 2000, 112, 2351.

5. Kim, T. H.; Kim, D. G.; Lee, M.; Lee, T. S. Tetrahedron 2010, 66, 1667.

6. Sangeetha, N.; Maitra, U. Chem. Soc. Rev. 2005, 34, 821.

7. Kato, T.; Frechet, J. M. J. J. Am. Chem. Soc. 1989, 111, 8533.

8. Vintiloiu, A.; Leroux, J. C. J. Controlled Release 2008, 125, 179.

9. Kobayashi, S.; Hamasaki, N.; Suzuki, M.; Kimura, M.; Shirai, H.; Hanabusa, K. J. Am. Chem. Soc. 2002, 124, 6550.

10. Llusar, M.; Roux, C.; Pozzo, J. L.; Sanchez, C. J. Mater. Chem. 2003, 13,442 .

11. Jung, J. H.; Shinkai, S.; Shimizu, T. Chem. Mater. 2003, 15, 2141.

12. Yang, Y.; Suzuki, M.; Kimura, M.; Shirai, H.; Hanabusa, K. Chem. Commun. 2004, 1332.

13. Suzuki, M.; Sakakibara, Y.; Kobayashi, S.; Kimura, M.; Shirai, H.; Hanabusa, K. Polym. J. 2003, 34, 474.

14. Kato, T. Science 2002, 295, 2414.

15. de Jong, J. J. D.; Lucas, L. N.; Kellogg, R. M.; van Esch, J. H.; Feringa, B. L. Science 2004, 304, 278

16. Hanabusa, K.; Hiratsuka, K.; Kimura, M.; Shirai, H. Chem. Mater. 1999, 11, 649 .

17. Kubo, W.; Kambe, S.; Nakade, S.; Kitamura, T.; Hanabusa, K.; Wada, Y.; Yanagida, S. J. Phys. Chem. B 2003, 107, 4374

18. Shibata, Y.; Kato, T.; Kado, T.; Shiratuchi, R.; Takashima, W.; Kaneto, K.; Hayase, S. Chem. Commun. 2003, 2730.

19. Duan, P.; Liu, M. Langmuir 2009, 25, 8706.

20. (a) Smith, D. K.; Diederich, F. Chem. Eur. J. 1998, 4, 1353. (b) Hirst, A. R.; Smith, D. K.; Feiters, M. C.; Geurts, H. P. M.; Wright, A. C. J. Am. Chem. Soc. 2003, 125, 9010. (c) Love, C. S.; Hirst, A. R.; Chechik, V.; Smith, D. K.; Ashworth, I.; Brennan, C. Langmuir 2004, 20, 6580. (d) Hirst, A. R.; Smith, D. K.; Feiters, M. C.; Geurts, H. P. M. Chem. Eur. J. 2004, 10, 5901.

21. (a) Hanabusa, K.; Matsumoto, M.; Kimura, M.; Kakehi, A.; Shirai, H. J. Colloid Interface Sci. 2000, 224, 231. (b) Kim, C.; Kim, K. T.; Chang, Y. H.; Song, H.; Cho, T. Y.; Jeon, H. J. J. Am. Chem. Soc. 2001, 123, 5586. (c) Chow, H. F.; Zhang, J. Tetrahedron 2005, 61, 11279. (d) Chow, H. F.; Zhang, J. Chem. Eur. J. 2005, 11, 5817. (e) Palui, G.; Simon, F. X.; Schmutz, M.; Mesini, P.; Banerjee, A. Tetrahedron 2008, 64, 175.

22. Motulsky, A.; Lafleur, M.; Couffin-Hoarau, A.C.; Hoarau, D.; Boury, F.; Benoit, J. P.; Leroux, J. C. Biomaterials 2005, 26, 6242.

23. van Esch, J.; Schoonbeek, F.; de Loos, M.; Kooijman, H.; Spek, A. L.; Kellogg, R. M.; Feringa, B. L. Chem. Eur. J. 1999, 5, 937.

24. Terech, P.; Rossat, C.; Volino, F. J. Colloid Interface Sci. 2000, 227, 363.

25. Carré, A.; Le Grel, P.; Baudy-Floc'h, M. Tetrahedron Lett. 2001, $42,1887$.

26. Seo, S. H.; Chang, J. Y. Chem. Mater. 2005, 17, 3249.

27. Hirst, A. R.; Smith, D. K.; Feiters, M. C.; Geurts, H. P. M. Langmuir 2004, 20, 7070 .

28. Suzuki, M.; Sato, T.; Kurose, A.; Shirai, H.; Hanabusa, K. Tetrahedron Lett. 2005, 46, 2741.

29. Tan, C.; Su, L.; Lu, R.; Xue, P.; Bao, C.; Liu, X.; Zhao, Y. J. Mol. Liq. 2006, 124, 32.

30. Jang, W.-D.; Jiang, D.-L.; Aida, T. J. Am. Chem. Soc. 2000, 122, 323

31. Jang, W.-D.; Aida, T. Macromolecules 2003, 36, 8461.

32. Estroff, L. A.; Leiserowitz, L.; Addadi, L.; Weiner, S.; Hamilton, A. D. Adv. Mater. 2003, 15, 38. 